\title{
Frequency of tuberculosis among diabetic patients in the People's Republic of China
}

\author{
This article was published in the following Dove Press journal: \\ Therapeutics and Clinical Risk Management \\ 10 January 2014 \\ Number of times this article has been viewed
}

\author{
Hong-Tian Wang' \\ Jing Zhang' \\ Ling-Chao Ji' \\ Shao-Hua You' \\ Yin $\mathrm{Bai}^{\prime}$ \\ Wei Dai \\ Zhong-Yuan Wang ${ }^{3}$
}

'Department of Otorhinolaryngology, Head, and Neck Surgery, Chinese PLA General Hospital, ${ }^{2}$ Department of Medical Record Administration, Chinese PLA General Hospital,

${ }^{3}$ The 3rd TB Department, Chinese PLA 309 Hospital, Beijing, People's Republic of China
Correspondence: Hong-Tian Wang Department of Otorhinolaryngology Head Neck Surgery, Chinese PLA

General Hospital, No 28, Fuxing Road, Beijing I00853, People's Republic of China

Tel +86 I3 911681469

Fax +86 I0 68I56974

Emailwht30I@263.net

Zhong-Yuan Wang

Department of Medical Record

Administration, Chinese PLA General

Hospital, Beijing 100853 ,

People's Republic of China

Tel +86 I3 |46508463

Emailwzy2004177@sina.com

\begin{abstract}
The People's Republic of China has nearly the highest incidence of both diabetes mellitus (DM) and tuberculosis (TB) worldwide. DM increases the risk of TB by two to three times and adversely affects TB treatment outcomes. The increasing epidemic of DM in the People's Republic of China is due to decreased physical activity, unhealthy diet, and obesity. Over the last 20 years, the excellent free China National Tuberculosis Program has been set up, and the "DOTS" (directly observed treatment + short-course chemotherapy) model for TB control has successfully reduced the burden of TB, but the disease is still a considerable problem. Given the high burden of TB and DM in the People's Republic of China and the relationship between the two diseases, it is sensible to screen DM patients for TB. A bidirectional screening of the two diseases was conducted in the People's Republic of China from 2011 to 2012, which identified a TB incidence in patients with DM of about 958 per 100,000. Here, we report the findings of our recent study on the incidence of TB among diabetic patients in the People's Republic of China. The data agree with those of previous reports.
\end{abstract}

Keywords: TB, diabetes mellitus, complications, screening

\section{Introduction}

The incidences of diabetes mellitus (DM) and tuberculosis (TB) are increasing, representing a serious threat to human longevity and health. Further, the prevalence, morbidity, mortality, and overall health hazards have increased in recent years. The number of DM patients worldwide has been estimated at about 347 million, ${ }^{1}$ with about 7 million of those classified as new cases; additionally, up to 2008, 3.9 million people had died from DM, with $80 \%$ of the deaths occurring in low- and middleincome countries. ${ }^{2}$ It is expected that by 2025 , the number of patients with DM in India, the People's Republic of China, Pakistan, and Mexico will increase by $200 \%$, and the number of patients with DM in India and the People's Republic of China will account for one-third of the total number of patients with DM worldwide. By 2030, the estimated number of DM patients will be about 438 million according to the current rate of growth, with $80 \%$ of new DM patients living in developing countries. Frighteningly, the World Health Organization (WHO) projects that DM will be the seventh leading cause of death by $2030 .^{3}$

The WHO declared TB a "global health emergency" in 1993, and in 2006, the Stop TB Partnership developed a global plan to stop TB that aims to save 14 million lives between its launch and 2015. ${ }^{4}$ A number of targets they have set are not likely to be achieved by 2015, largely due to the increase in DM-associated TB and the emergence of multi-drug resistant tuberculosis (MDR-TB). ${ }^{5}$ 
Although TB was once effectively controlled, the incidence in many countries rebounded in the 1980s and it has again become a major disease threatening public health. In addition to cases with typical symptoms, the number of nontypical TB cases is increasing significantly, and these are often associated with a chronic dry cough (pulmonary tuberculosis $[\mathrm{PTB}]$ ) and chronic hoarseness (laryngeal TB). ${ }^{6}$ Patients with nontypical TB symptoms often consult with otolaryngologists; therefore, doctors from all departments should be well aware of all possible symptoms of TB and should know that patients with DM are at a high risk of $\mathrm{TB}^{7}$ and that $\mathrm{TB}$ can increase the occurrence and development of DM. ${ }^{8}$ More attention is being paid to the coexistence of these two diseases by investigators, public health organizations, governments, and policy makers.

A previous study has demonstrated that DM not only increases the risk of TB but also adversely affects anti-TB treatment. ${ }^{9}$ DM greatly diminishes the immune function of the human body, causing decreased protein synthesis and increased protein consumption, leading to a decreased ability to produce immunoglobulin and hindering lymphocyte transformation for immune protection. The populations of $\mathrm{T}$ cells, $\mathrm{B}$ cells, and antibodies are reduced and their functions are impaired.$^{10}$ Simultaneously, hyperglycemia can decrease the mobility, adhesion, and bactericidal phagocytosis of white blood cells. TB is more likely to occur in young, thin, and frail patients with DM, lipidemia, or vitamin A deficiency. Increased blood fatty acids provide good nutrition for tubercle bacillus proliferation. Vitamin A deficiency also facilitates Mycobacterium tuberculosis infection, as the bacterium is resistant to immune cells. ${ }^{11}$ Vitamin A also influences the immune system and affects autoimmunity. One study found that blood retinol levels in type 1 diabetic rats were lower than in controls, indicating a close relationship between type $1 \mathrm{DM}$ and vitamin A deficiency. ${ }^{12}$

The $D R B 1^{*} 09$ allele is susceptive to PTB complicated with type $2 \mathrm{DM}$, while the $D Q B 1 * 05$ allele may be protective to PTB complicated with type $2 \mathrm{DM}$. The $D R B 1 * 09$ and $D Q B 1 * 05$ alleles may affect the incidence of PTB complicated with type $2 \mathrm{DM}$, or other real effect genes may link with them. ${ }^{13}$ Gonzalez-Curiel et al ${ }^{14}$ found that antimicrobialpeptide gene expression increases during progressive TB, which could be used as a biomarker for reactivation. In contrast, patients with type 2 DM have a lower gene expression of antimicrobial peptides, suggesting that these patients have an enhanced risk for TB reactivation. Two genes, $H K 2$ and $C D 28$, have been considered potential culprits in
DM-increased TB susceptibility. ${ }^{15}$ Compared with pre-DM status, the expression of both genes in DM decreased in each individual without exception. The $H K 2$ gene encodes hexokinase 2, which is a critical mediator of aerobic glycolysis, the unique energy source for macrophages. HK2 has been implicated in the development of insulin resistance and DM in experimental studies. ${ }^{15}$ Decreased expression of $H K 2$ may impair macrophage function, thus increasing the risk of TB. The $C D 28$ gene encodes T-cell antigen cluster of differentiation 28 . The T-helper (Th)1 response plays a key role in activating macrophages in immunity against TB. After phagocytizing $M t b$, proinflammatory macrophages present mycobacterial antigens to the T-cell receptors on the surfaces of cluster of differentiation (CD)4+ T lymphocytes. With costimulation by interleukin (IL)-12, mycobacterial antigens activate naïve CD4+ $\mathrm{T}$ cells and induce the generation of Th1 cells. In this process, the activation of $\mathrm{T}$ lymphocytes by the T-cell receptor complex after antigen recognition requires co-stimulation by $C D 28$. Decreased $C D 28$ expression in DM may impair CD4+T-cell activation and the Th1 response, thus increasing susceptibility to TB. ${ }^{16,17}$

\section{TB in the People's Republic of China}

The People's Republic of China has the second highest incidence of TB worldwide, ranking second only to India. There were 1 million cases of TB and 47,000 deaths from the disease in the People's Republic of China in 2011.18 The Tibet Autonomous Region has the highest TB prevalence rate. ${ }^{6}$ In the People's Republic of China, resistance to TB drugs has been reported at a rate of more than $46 \% .{ }^{8}$ In 2011 , the WHO and the International Union Against Tuberculosis and Lung Disease launched the Collaborative Framework for Care and Control of Tuberculosis and Diabetes. ${ }^{19,20}$ In 2010, the People's Republic of China was estimated to have 1 million incident cases of TB, with $6 \%$ of new cases and $26 \%$ of retreatment cases exhibiting MDR-TB. ${ }^{15}$

Mehra et $\mathrm{al}^{21}$ used the Tuberculosis Disease Transmission Model to estimate the future drug-susceptible tuberculosis (DS-TB) and MDR-TB burden. The model predicts that by 2050 in the People's Republic of China, the incidence, prevalence, and mortality of DS-TB will decrease by $32 \%$, $50 \%$, and $41 \%$, respectively, whereas those of MDR-TB will increase by $60 \%, 48 \%$, and $35 \%$, respectively. Reduced DS-TB rates will be a result of high rates of treatment and cure, leading to a decrease in the prevalence of latent TB infection, while the increase in MDR-TB will be due to inappropriate treatment, leading to a high rate of transmission of 
infection and an increased prevalence of latent TB infection. Therefore, improvements in the diagnosis and treatment of MDR-TB are needed. In addition, the incidence of TB is increasing with the increase in DM, chronic diseases such as AIDS, and increased drug resistance. Although over the last 20 years the People's Republic of China has successfully reduced its TB burden with its excellent free China National Tuberculosis Program (incorporating the "DOTS" [directly observed treatment + short-course chemotherapy] model for TB control), the disease is still a considerable problem. ${ }^{22}$

\section{DM in the People's Republic of China}

Having surpassed India, the People's Republic of China now has the largest number of DM patients worldwide. ${ }^{23}$ The prevalence of DM in the People's Republic of China has increased rapidly from $<1 \%$ in the 1980 s to $4.5 \%$ in 2002 and $9.7 \%$ in $2010 .{ }^{24}$ The prevalence of pre-DM (a condition in which blood glucose levels are higher than normal, but not high enough to be classified as full-blown DM) was $15.5 \% .{ }^{24}$ The People's Republic of China has 92.4 million adults with DM (50.2 million men and 42.2 million women) and 148.2 million adults with pre-DM (76.1 million men and 72.1 million women) over 20 years old. ${ }^{24}$ City residents have a higher prevalence of DM than rural residents (11.4\% versus $8.2 \%){ }^{24}$ In contrast, the prevalence of pre-DM among rural residents is much higher than in city residents. ${ }^{25}$ The prevalence of DM increases with increasing age and increasing weight. DM is a major risk factor for cardiovascular disease and is also a well-known risk factor for active TB (doubling or tripling the risk). ${ }^{25}$ TB patients with DM also have worse treatment outcomes than those without DM, which delays sputum culture conversion and increases the risk of both death and recurrent disease after successful treatment. ${ }^{25}$

\section{TB screening in DM patients in the People's Republic of China}

A survey was carried out by Lin et al in 2011-2012 in which five DM clinics were selected to represent the central, east, northwest, and southwest of mainland China. ${ }^{26}$ Patients aged 14 years or older diagnosed with DM and treated in the five DM clinics were enrolled from September 2011 to the end of March 2012. The screening for active TB followed the guidelines of the China National Tuberculosis Program (NTP). The screening was based on five questions regarding symptoms: 1) cough for longer than 2 weeks, 2) night sweats for 4 weeks or longer, 3) fever for 4 weeks or longer, 4) weight loss over the previous 4 weeks, and 5) any suspicion of active TB to account for extra-pulmonary TB. Patients with positive symptoms (an affirmative answer to any of the five questions) were referred to TB clinics for further investigation. When the diagnosis of active TB was made using sputum-smear microscopy for acid-fast bacilli (AFB) and chest radiography, the patient was referred to the NTP for registration and treatment. Between $68 \%$ and $79 \%$ of patients with DM were recorded as having been screened for TB. Of the 15,342 patients screened in the study, seven were identified as having TB and were receiving anti-TB treatment, 92 had positive symptoms ( $0.6 \%$ of those screened), 88 were referred for TB investigation (four were not referred for personal reasons), and 48 were newly diagnosed with TB (55\% of those screened). All except one of these patients were started on anti-TB treatment, with one patient being lost to follow-up after diagnosis. A total of $55 \mathrm{DM}$ patients (established and new) were identified as having TB: 40 with new and 15 with recurrent TB, 28 with smear-positive PTB, 24 with smear-negative PTB, and three with extra-pulmonary TB. The frequency of TB among patients with DM in the People's Republic of China was about 958 per 100,000. Other risk factors for TB - including HIV, steroid use, and immunocompromised states that may coexist with DM - were ruled out in screening patients with DM for TB.

\section{DM screening in TB patients in the People's Republic of China}

A survey was carried out by $\mathrm{Li}$ et $\mathrm{al}^{20}$ in six TB clinics in the People's Republic of China. Patients aged 15 years and older were consecutively diagnosed and registered with TB from September 1, 2011 up to March 31, 2012. A total of 8,886 patients with TB were first asked whether they had DM. If the answer was no, they were screened with a

Table I Inpatients with tuberculosis (TB) and with TB + diabetes mellitus (DM) in the past I2 years at the Chinese PLA 309 Hospital, Beijing, People's Republic of China

\begin{tabular}{|c|c|c|c|c|c|c|c|c|c|c|c|c|c|}
\hline$\overline{\text { Year }}$ & 2001 & 2002 & 2003 & 2004 & 2005 & 2006 & 2007 & 2008 & 2009 & 2010 & 2011 & 2012 & Total \\
\hline $\mathrm{TB}(\mathrm{n})$ & 306 & 362 & 217 & 341 & 361 & 421 & 560 & 586 & 704 & 807 & 908 & 848 & 6,421 \\
\hline$T B+D M(n)$ & 22 & 21 & 13 & 28 & 30 & 35 & 40 & 39 & 51 & 82 & 101 & 105 & 567 \\
\hline$(\mathrm{TB}+\mathrm{DM}) / \mathrm{TB} \times 100 \%(\%)$ & 7.2 & 5.8 & 6.0 & 8.2 & 8.3 & 8.3 & 7.1 & 6.65 & 7.2 & 10.2 & 11.1 & 12.4 & 8.8 \\
\hline
\end{tabular}


Table 2 Comparison of clinical findings between tuberculosis (TB) alone and TB + diabetes mellitus (DM) at the Chinese PLA 309 Hospital, Beijing, People's Republic of China

\begin{tabular}{lll}
\hline Clinical & TB & TB + DM \\
\hline Positive AFB in PTB & $913 / 3,934(23.2 \%)$ & $216 / 445(48.5 \%)$ \\
Serious cases & $194 / 5,854(3.3 \%)$ & $4 I / 567(7.2 \%)$ \\
Concurrent infection & $1,315 / 5,854(22.5 \%)$ & $236 / 567(4 I .6 \%)$ \\
Hospitalized death & $80 / 5,854(I .4 \%)$ & $7 / 567(I .2 \%)$ \\
Average age (years) & 45.03 & 56.07 \\
Average hospitalization (days) & 27.48 & 27.6 \\
\hline
\end{tabular}

Abbreviations: AFB, acid-fast bacillus; PTB, pulmonary tuberculosis.

random blood glucose test followed by fasting blood glucose (FBG) test in those with a random blood glucose test result of $\geq 110 \mathrm{mg} / \mathrm{dL}$ (one facility) or with an initial FBG (five facilities). Those with an FBG test result of $\geq 126 \mathrm{mg} / \mathrm{dL}$ were referred for a second FBG. Altogether, 1,090 (12.4\%) patients with TB + DM were identified, of whom $863(9.7 \%)$ had a known diagnosis of DM. Of the 8,023 patients who needed screening for DM, 7,947 (99\%) were screened. A new diagnosis of DM was made in 227 patients $(2.9 \%$ of screened patients) and 575 (7.8\%) persons had impaired fasting glucose (FBG $110-126 \mathrm{mg} / \mathrm{dL}$ ). The prevalence of DM in patients with TB was significantly higher than that in healthy people.

Recently, we analyzed data on TB and DM in the past 12 years (January 2001 to December 2012) from The 3rd TB Department, Chinese PLA 309 Hospital, Beijing, People's Republic of China (Tables 1 and 2). The total number of TB cases was 6,421 (males 3,632, females 2,789) and the total number of DM cases among these was 567 (males 406, females 161). The $8.8 \%$ prevalence of DM in patients with $\mathrm{TB}$ was much higher than in patients without TB. We found that the number of TB and TB + DM cases changed year by year. TB cases and TB + DM cases ranked highest in 2011 and in 2012, respectively. The lowest numbers for both were in 2003 (many SARS [severe acute respiratory syndrome] patients were treated that year). The average age of the TB + DM patients was 56.07 years (17-87 years). The average age of TB patients was 45.03 years (21-84 years). Males were overrepresented in the
TB + DM group, compared to the TB-only group. There were 216 cases (48.5\%) positive for AFB among 445 cases with PTB, and the positive rate in the DM group was obviously higher than that in the TB-only group. There were 41 serious cases of DM (7.2\%), which was higher than in the TB-only group (3.3\%). In the DM group, 236 cases (41.6\%) had concurrent infections with other bacteria, viruses, or fungi, but the TB-only group had 1,315 patients with other infections, with a rate of $22.5 \%$, clearly lower than the DM group. However, the hospitalized death rates in the two groups were very similar, at $1.2 \%$ and $1.4 \%$ for the TB-only group and the DM-only group, and the average periods of hospitalization in these two groups were also similar at 27.48 days and 27.6 days, respectively. Our analysis indicates that DM plays a very important role in TB clinical findings including a positive AFB smear, seriousness of clinical condition, concurrent infections, and final outcome.

We conducted another investigation of DM and TB from January 2003 to December 2012 in our DM clinic at the Chinese PLA General Hospital, Beijing, People's Republic of China (Table 3), which identified 15,302 ward patients with $\mathrm{DM}$ and 758 (4.95\%) ward patients with DM + TB in the past 10 years. The number of ward patients with DM increased yearly and the number of ward patients with DM + TB also increased yearly. Our data are in line with a previous report. ${ }^{20}$ We also strictly ruled out other risk factors for TB including HIV, steroid use, and immunocompromised states that may coexist in patients with DM and TB.

Table 3 Inpatients with diabetes mellitus (DM) and with DM + tuberculosis (TB) in the past 10 years at the Chinese PLA General Hospital, Beijing, People's Republic of China

\begin{tabular}{llllllllllll}
\hline Year & $\mathbf{2 0 0 3}$ & $\mathbf{2 0 0 4}$ & $\mathbf{2 0 0 5}$ & $\mathbf{2 0 0 6}$ & $\mathbf{2 0 0 7}$ & $\mathbf{2 0 0 8}$ & $\mathbf{2 0 0 9}$ & $\mathbf{2 0 1 0}$ & $\mathbf{2 0 1 \text { I }}$ & $\mathbf{2 0 1 2}$ & Total \\
\hline DM $(\mathrm{n})$ & 687 & 817 & 962 & $\mathrm{I}, \mathrm{I} 27$ & $\mathrm{I}, 232$ & $\mathrm{I}, 478$ & 1,744 & 2,046 & 2,403 & 2,806 & 15,302 \\
$\mathrm{DM}+\mathrm{TB}(\mathrm{n})$ & 13 & 20 & 32 & 24 & 35 & 53 & $\mathbf{7 2}$ & 149 & 176 & 184 & 758 \\
$(\mathrm{~TB}+\mathrm{DM}) / \mathrm{TB} \times 100 \%(\%)$ & 1.9 & 2.4 & 3.3 & 2.1 & 2.8 & 3.6 & 4.1 & 7.3 & 7.3 & 6.6 & 4.95 \\
\hline
\end{tabular}




\section{Conclusion}

The frequency of TB among patients with DM in the People's Republic of China is about 958 per 100,000 people, which is much higher than that of the general population ( 78 per 100,000), as reported by the WHO in 2011. ${ }^{18}$ Active TB screening in patients with DM may increase earlier detection, facilitating better treatment of TB. It also may improve clinical outcomes with anti-TB treatment and DM routine care. Moreover, early diagnosis of TB in DM patients will reduce the risk of TB transmission. The introduction of active TB screening in DM patients may lead to better use of the well-established DOTS system to monitor, record, and report information about TB patients. Bidirectional screening for DM and TB should be of significant benefit in the People's Republic of China.

\section{Disclosure}

The authors declare no conflicts of interest in this work.

\section{References}

1. Danaei G, Finucane MM, Lu Y, et al; Global Burden of Metabolic Risk Factors of Chronic Diseases Collaborating Group (Blood Glucose). National, regional, and global trends in fasting plasma glucose and diabetes prevalence since 1980: systematic analysis of health examination surveys and epidemiological studies with 370 country-years and 2.7 million participants. Lancet. 2011;378(9785):31-40.

2. Mathers CD, Loncar D. Projections of global mortality and burden of disease from 2002 to 2030. PLoS Med. 2006;3(11):e442.

3. World Health Organization (WHO). Global Status Report on Noncommunicable Diseases 2010. Geneva: WHO; 2011. Available from: http://whqlibdoc.who.int/publications/2011/9789240686458_eng.pdf. Accessed November 5, 2013.

4. Stop TB Partnership. The Global Plan to Stop TB: Transforming the Fight Towards Elimination of Tuberculosis. Geneva: WHO; nd. Available from: http://www.stoptb.org/assets/documents/global/plan/TB_ GlobalPlanToStopTB2011-2015.pdf. Accessed November 5, 2013.

5. Lawn SD, Zumla AI. Tuberculosis. Lancet. 2011;378(9785):57-72.

6. Wang H, Bai Z, Wang K, et al. [Secondary laryngeal tuberculosis at high altitudes of Tibet]. Lin Chung Er Bi Yan Hou Tou Jing Wai Ke Za Zhi. 2011;25(21):977-981. Chinese.

7. Balakrishnan S, Vijayan S, Nair S, et al. High diabetes prevalence among tuberculosis cases in Kerala, India. PLoS One. 2012;7(10):e46502.

8. Leung CC, Lam TH, Chan WM, et al. Diabetic control and risk of tuberculosis: a cohort study. Am J Epidemiol. 2008;167(12): 1486-1494.

9. Baker MA, Harries AD, Jeon CY, et al. The impact of diabetes on tuberculosis treatment outcomes: a systematic review. BMC Med. 2011;9:81.
10. Alcorn T, Ouyang Y. Diabetes saps health and wealth from China's rise. Lancet. 2012;379(9833):2227-2228.

11. Jason J, Archibald LK, Nwanyanwu OC, et al. Vitamin A levels and immunity in humans. Clin Diagn Lab Immunol. 2002;9(3):616-621.

12. Takahashi N, Takasu S. A close relationship between type 1 diabetes and vitamin A-deficiency and matrix metalloproteinase and hyaluronidase activities in skin tissues. Exp Dermatol. 2011;20(11):899-904.

13. Zhao Y, Duanmu H, Song C. [Analysis of the association between HLA-DRB(1), DQB(1) gene and pulmonary tuberculosis complicated with diabetes mellitus]. Zhonghua Jie He He Hu Xi Za Zhi. 2001;24(2): 75-79. Chinese.

14. Gonzalez-Curiel I, Castañeda-Delgado J, Lopez-Lopez N, et al. Differential expression of antimicrobial peptides in active and latent tuberculosis and its relationship with diabetes mellitus. Hum Immunol. 2011;72(8):656-662.

15. Lehto M, Xiang K, Stoffel M, et al. Human hexokinase II: localization of the polymorphic gene to chromosome 2. Diabetologia. 1993;36(12):1299-1302.

16. Thye T, Vannberg FO, Wong SH, et al; African TB Genetics Consortium; Wellcome Trust Case Control Consortium, Morris AP, Meyer CG, et al. Genome-wide association analyses identifies a susceptibility locus for tuberculosis on chromosome 18q11.2. Nat Genet. 2010;42:739-741.

17. Qu HQ, Rentfro AR, Lu Y, et al. Host susceptibility to tuberculosis: insights from a longitudinal study of gene expression in diabetes. Int $J$ Tuberc Lung Dis. 2012;16(3):370-372.

18. WHO. WHO Report: Global Tuberculosis Control 2011. Geneva: WHO; 2011. Available from: http://www.who.int/entity/tb/publications/ global_report/2011/gtbr11_full.pdf. Accessed November 5, 2013.

19. Stop TB Department and Department of Chronic Diseases and Health Promotion WHO, International Union Against Tuberculosis and Lung Disease (IUATLD). Collaborative Framework for Care and Control of Tuberculosis and Diabetes. Geneva and Paris: WHO and IUATLD. Available from: http://whqlibdoc.who.int/publications/2011/9789241502252_eng.pdf. Accessed November 6, 2013.

20. Li L, Lin Y, Mi F, et al. Screening of patients with tuberculosis for diabetes mellitus in China. Trop Med Int Health. 2012;17(10):1294-1301.

21. Mehra M, Cossrow N, Kambili C, Underwood R, Makkar R, Potluri R. Assessment of tuberculosis burden in China using a dynamic disease simulation model. Int J Tuberc Lung Dis. 2013;17(9):1186-1194.

22. Ministry of Health and Chinese Centre on TB Control and Prevention. National Tuberculosis Control Programme Guidelines. Beijing: Peking Union Medical College; 2008.

23. Xu Y, Wang L, He J, et al; 2010 China Noncommunicable Disease Surveillance Group. Prevalence and control of diabetes in Chinese adults. JAMA. 2013;310(9):948-959.

24. Yang W, Lu J, Weng J, et al; China National Diabetes and Metabolic Disorders Study Group. Prevalence of diabetes among men and women in China. N Engl J Med. 2010;362(12):1090-1101.

25. Mayega RW, Guwatudde D, Makumbi F, et al. Diabetes and pre-diabetes among persons aged 35 to 60 years in eastern Uganda: prevalence and associated factors. PLoS One. 2013;8(8):e72554.

26. Lin Y, Li L, Mi F, et al. Screening patients with Diabetes Mellitus for Tuberculosis in China. Trop Med Int Health. 2012;17(10): 1302-1308.
Therapeutics and Clinical Risk Management

\section{Publish your work in this journal}

Therapeutics and Clinical Risk Management is an international, peerreviewed journal of clinical therapeutics and risk management, focusing on concise rapid reporting of clinical studies in all therapeutic areas, outcomes, safety, and programs for the effective, safe, and sustained use of medicines. This journal is indexed on PubMed Central, CAS,

\section{Dovepress}

EMBase, Scopus and the Elsevier Bibliographic databases. The manuscript management system is completely online and includes a very quick and fair peer-review system, which is all easy to use. Visit http://www.dovepress.com/testimonials.php to read real quotes from published authors. 